\title{
THE APPLICABILITY OF FINITE HOMOGENEOUS MARKOV PROCESSES IN THE STUDY OF CONSUMER LOYALTY
}

\author{
Dr Swapna Datta Khan \\ Assistant Professor, Army Institute of Management, Kolkata;
}

Article DOI: https://doi.org/10.36713/epra6787

DOI No: 10.36713/epra6787

\begin{abstract}
Markov Processes are sequential events that are related to each other stochastically. Such events, also known as states, may be such that the probability of an event occurring depends only on the previous event and not on any event prior to that. This is known as the memoryless property of Markov Processes. Certain dynamic market conditions especially with respect to the Fast-Moving Consumer Goods Sector, the Telecommunications Sector may enable the use of finite and time-homogeneous Markov Processes to study the brand switching tendency of the consumer, and thus predict consumer loyalty. In this conceptual paper, we shall study how to predict brand switching tendencies using finite, time-homogeneous Markov Processes.
\end{abstract}

KEYWORDS: Markov Process, Brand Switching, Time-Homogeneous, Consumer Loyalty, Transition Matrix

\section{INTRODUCTION}

Let us consider a stochastic model listing sequential events such that the probability of an event depends on the previous event and not the ones before that. Such a memory-less stochastic model is called the Markov Chain or Markov Process, named after the Russian mathematician, Andrey Markov. Used to model changing systems, Markov Processes can be utilized to make effective predictions in a dynamic economic environment regarding brand switching tendencies and thus consumer loyalty towards a brand. (Markov chain, 2021)

Objective

To study the concept of finite time-homogeneous Markov Process and its applicability in predicting consumer loyalty

\section{RESEARCH METHODOLOGY}

The researcher studies conceptual readings within relevant literature and draws conclusions therein. The study illustrates using fictitious examples emphasizing mainly on the concept of how finite time-homogeneous Markov Processes could be used to predict brand loyalty.

\section{LITERATURE REVIEW: CONCEPTUAL READINGS ON MARKOV PROCESSES}

Let $\left\{\mathrm{X}\left(\mathrm{t}_{\mathrm{n}}\right): \mathrm{n}=1,2, \ldots\right\}$ be a set of Random Variables where $\mathrm{X}(\mathrm{t})$ stands for observation at time $\mathrm{t}$ defines a Stochastic Process, where the number of states, $\mathrm{n}$ may be finite. (Sharma, 2005) Markov Process is a system consisting of a set of objects and a set of states such that at any given time, an object must be in a state and the probability that an object moves between two states at any given time depends only on the two states. (Bronson \& 


\section{SJIF Impact Factor 2021: 8.013| ISI I.F.Value:1.241| Journal DOI: 10.36713/epra2016 ISSN: 2455-7838(Online) EPRA International Journal of Research and Development (IJRD)}

Volume: 6 | Issue: 4 | April 2021

- Peer Reviewed Journal

Naadimuthu, 2010) A Markov Process, is thus a stochastic process that has the property that the occurrence of a state depends only on the preceding state. Any Markov Process can be viewed as a series of $n$ experiments, with $n$ individual outcomes (also called states) and $\mathrm{P}\left(\mathrm{i}^{\text {th }} \text { experiment has a particular outcome) is a function of the (i-1) }\right)^{\text {th }}$ experiment. (Sharma, 2005)

The Markovian Property (memory-lessness) is thus: if $\mathrm{t}_{0}<\mathrm{t}_{1}<\ldots<\mathrm{t}_{\mathrm{n}}$ are $\mathrm{n}$ successive time periods, then P[X $\left(\mathrm{t}_{\mathrm{n}}\right)$ $\left.=\mathrm{x}_{\mathrm{n}} / \mathrm{X}\left(\mathrm{t}_{\mathrm{n}-1}\right)=\mathrm{x}_{\mathrm{n}-1}, \mathrm{X}\left(\mathrm{t}_{\mathrm{n}-2}\right)=\mathrm{x}_{\mathrm{n}-2}, \ldots, \mathrm{X}\left(\mathrm{t}_{0}\right)=\mathrm{x}_{0}\right]=\mathrm{P}\left[\mathrm{X}\left(\mathrm{t}_{\mathrm{n}}\right)=\mathrm{x}_{\mathrm{n}} / \mathrm{X}\left(\mathrm{t}_{\mathrm{n}-1}\right)=\mathrm{x}_{\mathrm{n}-1}\right] \square \mathrm{X}\left(\mathrm{t}_{\mathrm{i}}\right)$ (Sharma, 2005), (Markov Chains) The number of time periods, past the moment when the Markov Process begins correspond to the stages (states) of the Markov Process. If the number of the states of the Markov Process is countable, it is called a Markov Chain. A Markov Process with a finite number of states is called a Finite Markov Chain. (Bronson \& Naadimuthu, 2010)

The probability of moving from one state to another or remaining in the same state is called the Transition Probability. The transition probability of moving from state $\mathrm{i}$ to $\mathrm{j}$ could be denoted as $\mathrm{p}_{\mathrm{ij}}=\mathrm{P}\left[\mathrm{X}\left(\mathrm{t}_{\mathrm{j}}\right)=\mathrm{x}_{\mathrm{j}} / \mathrm{X}\left(\mathrm{t}_{\mathrm{i}}\right)=\mathrm{x}_{\mathrm{i}}\right]$ (Sharma, 2005)

The Matrix $\mathrm{P}=\left(\mathrm{p}_{\mathrm{ij}}\right)_{\mathrm{nxn}}$ is known as the (One-step) Transition Matrix, which is stochastic as each row adds to 1 or $\sum_{j=1}^{n} p i j=\sum_{j=1}^{n} \mathrm{P}[\mathrm{X}(\mathrm{t} \mathrm{j})=\mathrm{xj} / \mathrm{X}(\mathrm{ti})=\mathrm{xi}]=1$ (Bronson $\&$ Naadimuthu, 2010)

Further, if the Transition Probabilities are independent of the time $t$ or $\square$ a constant $p_{i j}=P\left[X\left(t_{j}\right)=x_{j} / X\left(t_{i}\right)=x_{i}\right]$ $\square \mathrm{t}$, then the Markov Chain is known to be homogeneous. (Klappenecker, 2018) A Markov Process of Order $\mathrm{n}$ is such that the probability of an outcome depends on the nth previous outcome. E.g.: In a second order Markov Process, the probability of an outcome depends on the two previous outcomes. (Sharma, 2005) While studying the brand switching cases and thus, consumer loyalty towards only $1^{\text {st }}$ order Markov Processes that are finite and homogeneous. (Sharma, 2005)

(Suppose $\mathrm{V}=\mathrm{a}$ non-zero vector and $\mathrm{A}$ is the matrix representation of the linear transformation of a vector space over a field into itself and $\mathrm{AV}=\lambda \mathrm{V}$ for some scalar $\lambda$, then $\lambda$ is the Eigen Value associated with $\mathrm{A} \& \mathrm{~V}$. (Eigen Values and Eigen Vectors)). If $\lambda$ is the Eigen Value of $P$, a stochastic matrix, then $|\lambda| \leq 1$. Also, $\square$ a vector $X \neq \mathrm{O}_{1 \times n}$ such that $\mathrm{XP}=\mathrm{X}$ and $\mathrm{X}$ is the Fixed Vector (or stationary vector) of $\mathrm{P}, \mathrm{P}$ being regular. (Bronson \& Naadimuthu, 2010) The positive integral power of a Stochastic Matrix is also Stochastic of $\mathrm{P}^{\mathrm{n}}$ is stochastic. (Bronson \& Naadimuthu, 2010) An example is shown in Figure 1.

In an Ergodic Markov Chain, it is possible to pass from one state to another in a finite number of steps. A regular Markov Chain is a special type of the ergodic Markov Chain. (Sharma, 2005) A Stochastic Matrix is Regular if one of its positive integral powers contains only positive values. (Bronson \& Naadimuthu, 2010)

Let $t_{i}=\left(t_{i 1}, t_{i 2}, \ldots ., t_{i n}\right){ }_{1 \times n}$ represent the State of a System at time period $i$. Then, $t_{0}$ will represent the initial state and $\mathrm{t}_{1}=\mathrm{t}_{0} \mathrm{P}$

$\mathrm{t}_{2}=\mathrm{t}_{1} \mathrm{P}=\mathrm{t}_{0} \mathrm{P}^{2}$

$\mathrm{t}_{\mathrm{n}}=\mathrm{t}_{\mathrm{n}-1} \mathrm{P}=\mathrm{t}_{0} \mathrm{Pn}$ (Bronson \& Naadimuthu, 2010)

In the set of equations above, we note that: $t_{n+1}=t_{n} P$. Thus, $\lim _{n \rightarrow \infty} t_{n+1}=\lim _{n \rightarrow \infty} t_{n} P=t P$ where $t$ is the Steady State Vector, representing Steady State Equilibrium of P

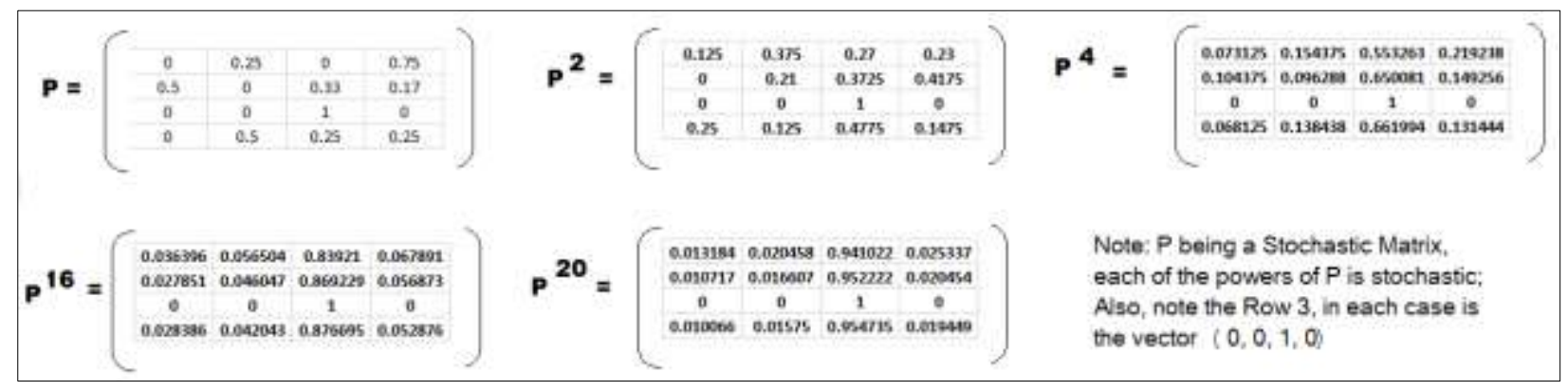

Figure 1: Stochastic Matrix and its powers 


\section{Literature Review: Related Studies that throw light on the estimation of the Transition Matrix}

A study of relevant literature shall enable an exploration as to how we may be able to estimate accurately the transition probabilities from available consumer and marketing data.

Written in 1969, this paper (Armstrong \& Farley, 1969) throws light on the technique of estimating transition probabilities and the goodness of fit of the Markov Model for forecasting market shares. The earliest methods of estimating the transition probabilities are considering runs of panel data, as shown in Figure 2 (for Brands A, B, C)

\section{Family 1-AAAAAABACAAA \\ Family 2-CBBBBBBBBA \\ Family 3-CCCCCCCBCAA}

Figure 2: Source: (Armstrong \& Farley, 1969)

Other mentioned approaches to estimation transition probabilities include the analysis of sets of summary statistics (of a family's purchases), categorize groups of purchasers into "loyalty classes" and asking questions like "given the purchase of brand A, which brand is likely to be purchased next?" (Armstrong \& Farley, 1969)

Discussion: Whatever the method, it is imperative to check the stability of the transition probabilities over time, impact of extraneous variables caused by marketing activities and whether the studied sample is representative of the population. It has been seen that if the period of study is short enough that the estimated transition probabilities are actually approximations of reality, then the Markov Model for forecasting market shares is fairly successful.

In their study, Awogbemi, Oloda, \& Osama, 2012 computed "Brand Insistence Rates" from a survey of 360 customers who gave their preferences for three types of soft drinks (F, M, MD) and computed the transition probabilities after the construction of a transition diagram as shown in Figure 3 below. (Awogbemi, Oloda, \& Osama, 2012)

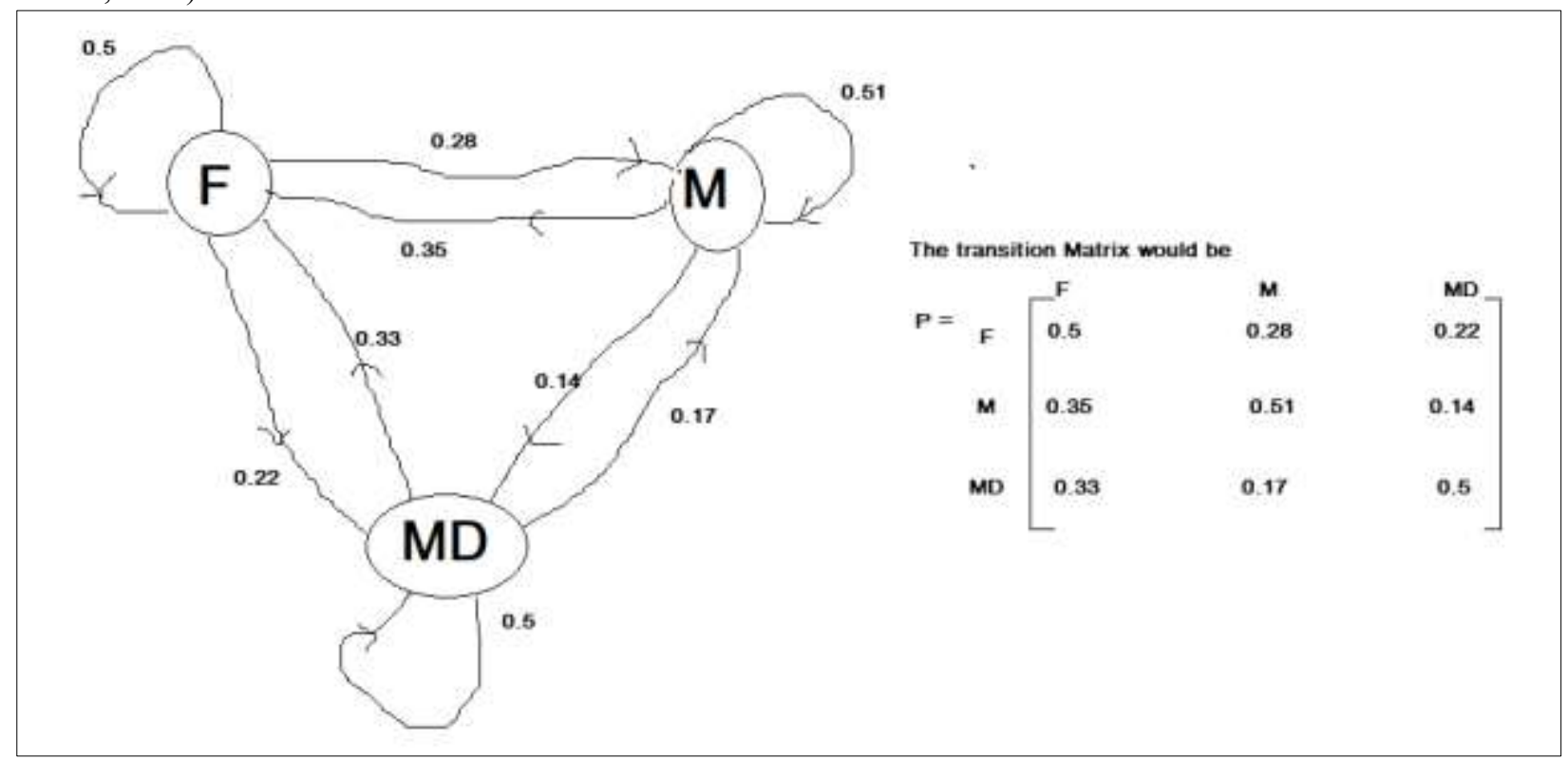

Figure 3: (Source: (Awogbemi, Oloda, \& Osama, 2012))

Bairagi \& Kakaty, 2016, in their paper assessed the preferences of 1010 respondent households towards 6 beverages over two time periods and computed two transition matrices (one for each time perion) and thereafter, conputed the final transition matrix as the mean of the two matrices. (Bairagi \& Kakaty, 2016) 


\section{SJIF Impact Factor 2021: 8.013| ISI I.F.Value:1.241| Journal DOI: 10.36713/epra2016 ISSN: 2455-7838(Online) EPRA International Journal of Research and Development (IJRD)}

Volume: 6 | Issue: 4 | April 2021

- Peer Reviewed Journal

Discussion:

- Two transition matrices show that the quality of homogeneity has been compromised in the Markov Process

- However, if the said method is extrapolated to moving averages over a sufficient number of time periods, we may be able to improve upon the homogeneity of the said Markov Process

- We could check the correlation between the corresponding transition probabilities

Chan, 2015 in his paper insisted that transition probabilities of homogeneous Markov Chains are computed using historical data. He took two time periods and in each time period, he computed a matrix showing the actual number of customers and the movement of customers two competing brands. He then estimated pij to be the average of the corresponding transition probabilities. The same is shown in the Figure 4. (Chan, MARKET SHARE MODELLING AND FORECASTING USING MARKOV CHAINS AND ALTERNATIVE MODELS, 2015)

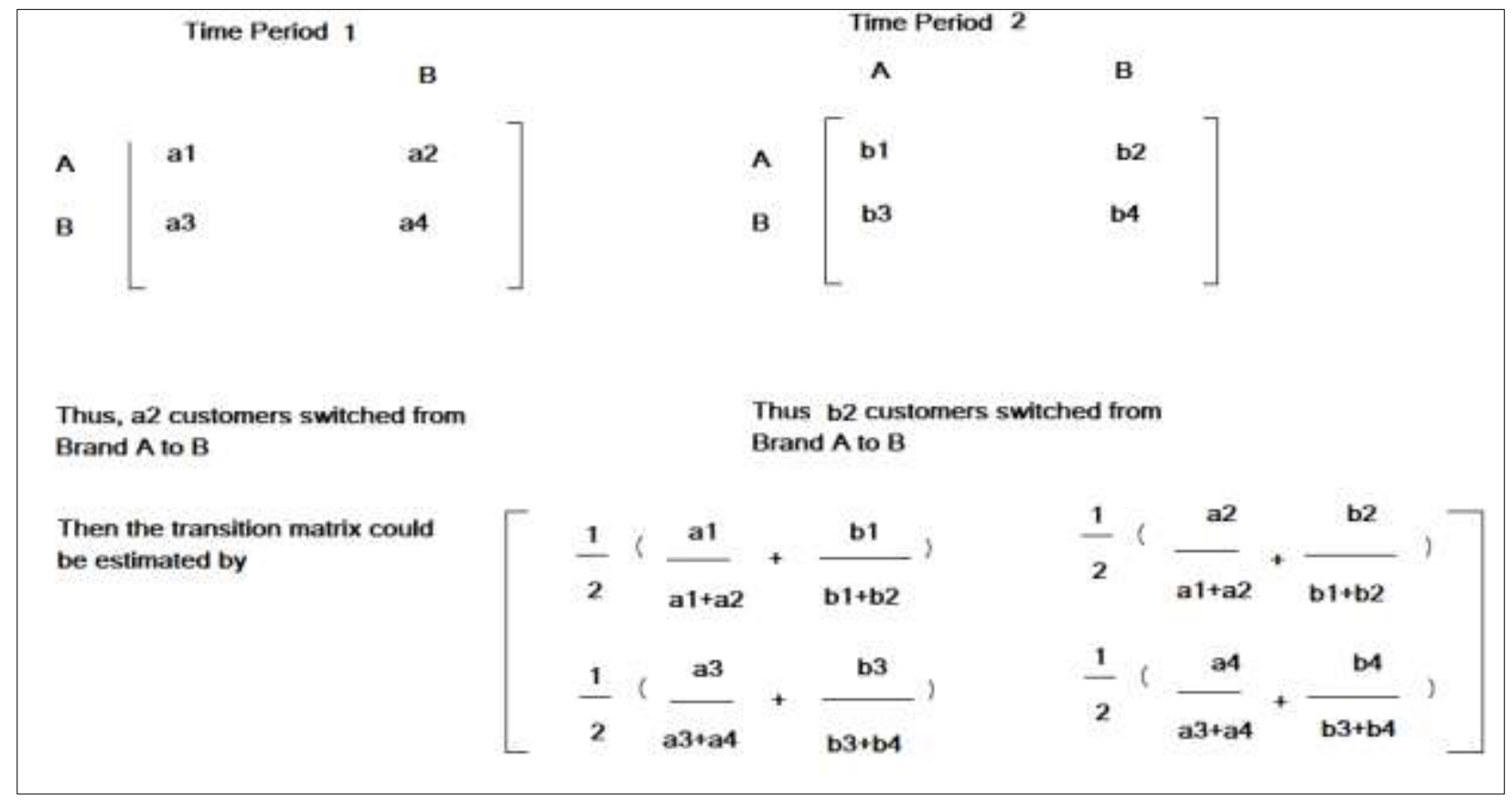

\section{Figure 4: A depiction of the estimation of transition probabilities, referencing (Chan, MARKET SHARE MODELLING AND FORECASTING USING MARKOV CHAINS AND ALTERNATIVE MODELS, 2015)}

Discussion: It may be noted that here too, the quality of homogeneity is likely to be compromised.

DELLAROCAS, ZHANG, \& AWAD, 2007 established a model that proceeded to forecast the success of a motion picture and proposed a family of diffusion models, which is a variant of the Bass Diffusion Model (Bass Diffusion Model). The Internet and Internet of Things have ensured that much data is available from user generated online content (UGC) and thus the measurement of consumer Word of Mouth (WOM) communication is eased. In their research, they have mentioned that UGC typically contributes towards the measurement of volume, valence and dispersion with respect to consumer-postings. Volume of UGC implies that more people speak about a product, Valence measures consumer attitude towards a product (positive versus negative) and Dispersion measures the spread of product information across communities. (DELLAROCAS, ZHANG, \& AWAD, 2007)

Discussion: In order to estimate the Transition Matrix, could we understand that $p_{i j}$ is a function of volume, valence and dispersion with respect to consumer postings?

Jones, 2005 says that assuming a first-order Markov Process may be restrictive if the measure under consideration (credit quality, in his research) responds to economic fundamentals. However, the usage of higher order Markov Processes requires complexity in data collection and processing. (Jones, 2005) 
SJIF Impact Factor 2021: 8.013| ISI I.F.Value:1.241| Journal DOI: 10.36713/epra2016 ISSN: 2455-7838(Online) EPRA International Journal of Research and Development (IJRD)

Volume: 6 | Issue: 4 | April 2021

- Peer Reviewed Journal

As per research of Jones, 2005, let us again consider the example mentioned in Figure 4. Jones, 2005, showed simplistically as to how to estimate the transition matrix using only count data between two time periods, as in Figure 5.

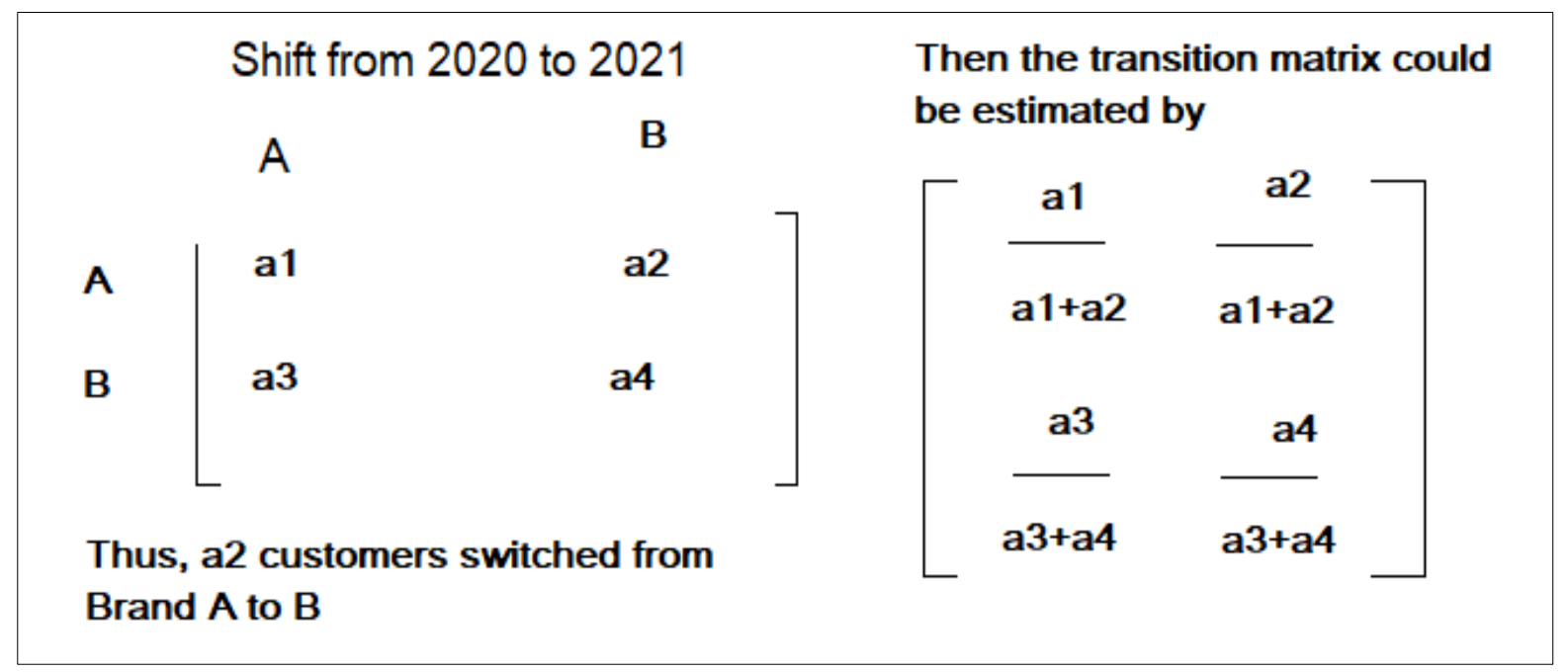

Figure 5: The creation of a Transition Matrix, when individual transitions are observed over a time period; based on (Jones, 2005)

Jones, 2005 further suggested that if the time series of observations is sufficiently long, the transition matrix could be estimated by quadratic programming methods. A simplistic version is depicted in Figure 6, based on the example in Figure 5.

$$
\begin{aligned}
& \mathrm{y} 2(2021)=\mathrm{y} 1(2020) \mathrm{p} 12+\mathrm{y} 2(2020) \mathrm{p} 22+\mathrm{u} 2(2021) \\
& y 2(2022)=y 1(2021) \quad p 12+y 2(2021) \quad p 22+u 2 \text { (2022) } \\
& y 2(2023)=y 1(2022) \quad p 12+y 2(2022) \quad p 22+u 2 \text { (2023) }
\end{aligned}
$$

Figure 6: Estimating the Transition Matrix from aggregate data, based on (Jones, 2005)

Umoh, Awa, \& Ebitu, 2013 in their research studied the brand switching tendencies of households regarding 5 brands of toothpaste. To estimate the transition probabilities, they studied the purchase sequence of households. (Umoh, Awa, \& Ebitu, 2013)

\section{FINDINGS AND CONCLUSIONS}

- The Markovian Property (memory-lessness) is defined by: if $\mathrm{t}_{0}<\mathrm{t}_{1}<\ldots<\mathrm{t}_{\mathrm{n}}$ are $\mathrm{n}$ successive time periods, then $\mathrm{P}\left[\mathrm{X}\left(\mathrm{t}_{\mathrm{n}}\right)=\mathrm{x}_{\mathrm{n}} / \mathrm{X}\left(\mathrm{t}_{\mathrm{n}-1}\right)=\mathrm{x}_{\mathrm{n}-1}, \mathrm{X}\left(\mathrm{t}_{\mathrm{n}-2}\right)=\mathrm{x}_{\mathrm{n}-2}, \ldots, \mathrm{X}\left(\mathrm{t}_{0}\right)=\mathrm{x}_{0}\right]=\mathrm{P}\left[\mathrm{X}\left(\mathrm{t}_{\mathrm{n}}\right)=\mathrm{x}_{\mathrm{n}} / \mathrm{X}\left(\mathrm{t}_{\mathrm{n}-1}\right)=\mathrm{x}_{\mathrm{n}-1}\right] \square \mathrm{X}\left(\mathrm{t}_{\mathrm{i}}\right)$

- The Transition Matrix, giving the probability of moving from 1 state to another, is given by $P=\left(p_{i j}\right)_{n \times n} w h e r e ~ p_{i j}$ $=\mathrm{P}[\mathrm{X}(\mathrm{tj})=\mathrm{xj} / \mathrm{X}(\mathrm{ti})=\mathrm{xi}]$ 


\section{SJIF Impact Factor 2021: 8.013| ISI I.F.Value:1.241| Journal DOI: 10.36713/epra2016 ISSN: 2455-7838(Online) EPRA International Journal of Research and Development (IJRD) \\ Volume: 6 | Issue: 4 | April 2021

- If the Transition Probabilities are independent of the time t or $\square$ a constant $\mathrm{p}_{\mathrm{ij}}=\mathrm{P}\left[\mathrm{X}\left(\mathrm{t}_{\mathrm{j}}\right)=\mathrm{x}_{\mathrm{j}} / \mathrm{X}\left(\mathrm{t}_{\mathrm{i}}\right)=\mathrm{x}_{\mathrm{i}}\right] \square \mathrm{t}$, then the Markov Chain is known to be homogeneous

- While studying the brand switching cases and thus, consumer loyalty towards only $1^{\text {st }}$ order Markov Processes that are finite and homogeneous

- In an Ergodic Markov Chain, it is possible to pass from one state to another in a finite number of steps

- A Stochastic Matrix is Regular if one of its positive integral powers contains only positive values

- $\square$ a vector $\mathrm{X} \neq \mathrm{O}_{1 \times n}$ such that $\mathrm{XP}=\mathrm{X}$ and $\mathrm{X}$ is the Fixed Vector (or stationary vector) of $\mathrm{P}, \mathrm{P}$ being regular and $X$ would be the fixed vector of $P$

- Markov Chain Analysis helps find the probability that a consumer will continue to use the brand he uses or the consumer will switch to a distant brand. It helps, thus predict the brand-switching tendency of a set of consumers and thus, forecast brand loyalty. (Pai, 2013), (Sharma, 2005)

We could thus say that in order to predict brand switching behaviour, the following assumptions are to be made:

- The Markov Chain is finite or the given system has a finite number of states

- None of the states should be absorbing or the Transition Matrix should be regular and Stochastic

- The Markov Process is a first order process

- The Markov Chain should be time-homogeneous or stationary or the transition probabilities should be constant over time.

- Uniform time periods: The change of one state to another happens only once during a time period and the time periods are identical in length (Vohra, 2017)

A generic example (Source: Researcher Contribution)

Suppose we have a set of $\mathrm{n}$ brands (of a certain product), say $A_{1}, A_{2}, \ldots . ., A_{n}$, whose market shares, as on 2020 are given by the vector $A_{20}=\left(a_{20-1}, a_{20-2}, \ldots . ., a_{20-n}\right)$ 1xn and the Transition Matrix governing the brand switching tendency is given by: $\mathrm{P}=$ (pij) ${ }_{n \times n}$, (assuming that during the year there is no incident of brand switching), then the market shares of the brands in the year 2021 would be given by the vector $A_{21}=\left(a_{21-1}, a_{21-2}, \ldots . ., a_{21-n}\right)$ 1xn, where $\mathrm{A}_{21}=\mathrm{A}_{20} \mathrm{P}$

Further, if "many years henceforth" (depicting steady state equilibrium), the market shares of the said brand are given $A_{1 \times n}=\left(a_{1}, a_{2}, \ldots . ., a_{n}\right)_{1 x n}$, we could determine $A$ by the system of linear equations generated by the equation $\mathrm{AP}=\mathrm{A}$ and also considering the fact that $\mathrm{A}_{1 \times n}$ would be a stochastic vector. It is rather intriguing to note that the Steady State Vector predicting the brands' long-term market share is entirely dependent on the transition matrix P. Also, if we were to study the brand switching tendency of consumers of a product using the Markov Analysis, we would need to know the initial state vector or the market shares of the brand and the transition matrix P.

The estimation of transition probabilities can be done in the following ways for the finite homogeneous Markov Process:

- By the study of purchase sequences of brands by a set of respondents and the creation of a Runs Vector; E.g.: $\{\mathrm{A}, \mathrm{A}, \mathrm{A}, \mathrm{B}, \mathrm{A}, \mathrm{C}, \mathrm{A}\}$ for brands A, B, C

- Surveying respondents who give their preferences over a time sequence. Thereafter the estimated transition probabilities could be aggregated from proportions of brand switching and brand choices in different time intervals or could also be computed using a measure computed from the actual counts of respondents' choices

- In each case, one has to note that the transition probabilities should not vary with time

- In case different transition matrices are computed over different equally partitioned periods within the time schedule, it would be intriguing to check the correlation between the corresponding transition probabilities

\section{REFERENCES}

1. Armstrong, J. S., \& Farley, J. U. (1969, Dec). A Note on the Use of Markov Chains in Forecasting Store Choice. Management Science, 16(4).

2. Awogbemi, C. A., Oloda, F. S., \& Osama, C. K. (2012). Modeling Brand Switching in Consumers' Products. Journal of Economics and Sustainable Development, 3(12), 82 - 86.

3. Bairagi, A., \& Kakaty, S. C. (2016, Jul-Aug). Analysis of Brand Loyalty using Homogeneous Markov Model. IOSR Journal of Economics and Finance (IOSR-JEF), 7(4), 06 - 09. 
SJIF Impact Factor 2021: 8.013| ISI I.F.Value:1.241| Journal DOI: 10.36713/epra2016 ISSN: 2455-7838(Online) EPRA International Journal of Research and Development (IJRD)

Volume: 6 | Issue: 4 | April 2021

- Peer Reviewed Journal

4. Bass Diffusion Model. (n.d.). Retrieved Feb 02, 2021, from https://en.wikipedia.org: https://en.wikipedia.org/wiki/Bass_diffusion_model

5. Bronson, R., \& Naadimuthu, G. (2010). Finite Markov Chains. In R. Bronson, \& G. Naadimuthu, Operations Research (pp. 369 - 377). New Delhi: Tata Mc Graw Hill Publishing Company Limited.

6. Chan, K. C. (2015, Aug). MARKET SHARE MODELLING AND FORECASTING USING MARKOV CHAINS AND ALTERNATIVE MODELS. International Journal of Innovative Computing, Information and Control, 11(4), 1205 1218.

7. DELLAROCAS, C., ZHANG, X., \& AWAD, N. F. (2007, Autumn). EXPLORING THE VALUE OF ONLINE PRODUCT REVIEWS IN FORECASTING SALES: THE CASE OF MOTION PICTURES. JOURNAL OF INTERACTIVE MARKETING, 21(4), 23 - 45. doi:10.1002/dir.20087

8. Eigen Values and Eigen Vectors. (n.d.). Retrieved Jan 29, 2021, from https://en.wikipedia.org: https://en.wikipedia.org/wiki/Eigenvalues_and_eigenvectors

9. Jones, M. T. (2005, Nov 01). Estimating Markov Transition Matrices Using Proportions Data : An Application to Credit Risk. Retrieved from https://www.imf.org: https://www.imf.org/en/Publications/WP/Issues/2016/12/31/Estimating-Markov-Transition-Matrices-UsingProportions-Data-An-Application-to-Credit-Risk-18387

10. Klappenecker, A. (2018). Markov Chains. Retrieved Jan 28, 2021, from https://people.engr.tamu.edu: https://people.engr.tamu.edu/andreas-klappenecker/csce658-s18/markov_chains.pdf

11. Markov chain. (2021, Apr 08). Retrieved from https://en.wikipedia.org: https://en.wikipedia.org/wiki/Markov_chain\#Economics_and_finance

12. Markov Chains. (n.d.). Retrieved Jan 28, 2021, from https://en.wikipedia.org: https://en.wikipedia.org/wiki/Markov_chain

13. Pai, P. P. (2013). Markov Chains. In P. P. Pai, Operations Research: Principles and Practice (pp. 613 - 643). New Delhi: Oxford University Press.

14. Sharma, S. D. (2005). Markov Analysis. In S. D. Sharma, Operations Research: Theory, Methods and Applications (pp. 512 - 525). Meerut: Kedar Nath Ram Nath \& Co. Publishers.

15. Umoh, G. I., Awa, H. O., \& Ebitu, P. T. (2013). Markovian Application to Brand Switching Behaviour: A Survey of Toothpaste. European Journal of Business and Management, 5(22), 110 - 124.

16. Vohra, N. D. (2017). Markov Chains. In N. D. Vohra, Quantitative Techniques in Management (pp. 799 - 835). Chennai: Mc Graw Hill Education (India) Private Limited. 